\title{
Effect of natural variations with respect of time interval in handwritings of individuals
}

\author{
SHRUTI GUPTA \\ Amity Institute of Forensic Science \\ Amity University, Noida, India \\ RAKESH K. GARG \\ Department of Forensic Science \\ Punjabi University, Patiala, India \\ SURINDER NATH \\ Department of Anthropology \\ Delhi University, New Delhi, India
}

\section{Introduction}

As the range of variations in writings of different dates or documents or instruments, appropriately called asynchronous writings, tends to be somewhat greater than that of synchronous (i.e., same date, place and time) executions. Since variation is an integral part of natural handwriting, no two samples of writing prepared by one person are identical in every detail. The extent of variation differs among writers and, consequently, natural variation forms an important element in the identification of handwriting. In some cases, variation is slight and occurs only in minor details of the writing; in other instances, the formation of letters and words will vary 
widely about a master pattern (Kelly and Lindblom, 2006). An individual's handwriting is made up of a complexity of habitual patterns that are repeated within a typical range of variation around the model patterns. In case of handwriting the proper consideration of natural variation is essential in order to distinguish between forged and genuine writing. Regardless of the class of problems, variation is ever present and must be accurately evaluated. It is as much as a basic part of the identification as each identifying characteristic itself (Hilton, 1982). Natural variations are due to the fact that our brain does not work like a computer. Natural variations are the imprecision with which the habits (discriminating elements) of the writer are executed on repeated occasions. Natural variations in writing diverge with the writer's condition, the writing conditions and may diverge with the nature of the document. When conditions are controlled, there is less variation between executions.

Accordingly, these fluctuations in writing are said to constitute a writer's range of natural variations. The matter of natural variations too could be broad or narrow, depending on the individual and the circumstances. Broad, as if occurs in less skillful writings, in this case only greater quantities of standards, and particularly collected standards, will properly portray its nature and its range. The variables affecting writing have a greater influence on less skillful writing than in skillful writing (Huber and Headrick, 1999).

Within the two extremes of life i.e., childhood and old age of an individual, there is severally different handwriting pattern, according to their fluency of their muscular movement and power of incoordination. They, furthermore, make it possible to tell one person's writing from another's handwriting. This way it is also possible to identify a person by his handwriting. Handwriting may, however, change due to many reasons and this causes more difficulties in the examination and identification of handwriting. Time is one of the reasons which may show natural variation in handwriting. Differences can be found in handwriting, written by a person now and years before.

Dawson (1987) in his research established an internal consistency in handwriting in his research. Shrihari (2002), on the basis of his study had concluded the significant role of individuality in handwriting along with variations shown in his research. 
Bafra (1998) had worked on 'the effect of time on handwriting', the results concluded very little difference and writing was more or less fixed even in terms of the range of natural variations and that the changes found could mislead to a wrong answer. Kapoor et al. (1985) conducted research on the study of the form and extent of natural variations in the genuine handwriting with the maturity in age, and concluded that though natural variations are encountered but some of the characteristics remain unaltered.

Various researches have been carried out on different aspects of questioned documents like typewriters and type written documents, forgeries and its types, disguised documents, components of inks, age of documents, different instruments and pen tips involved in producing writings, influence of drugs or alcohol on handwriting, computed methods and software for signatures and handwriting verification and identification etc. but "natural variations' are least explored area for research work and very little information is available on this aspect even though natural variations are regarded as basis and foremost criteria in establishing the authenticity of one's handwriting.

Usually, Document Experts are restricted to compare and form an opinion from the present and latest handwriting samples as admitted ones. It is expected that this research work will provide significant information and aid to document experts so that they could examine taking old handwritings as admitted for the purpose of comparisons especially for under those conditions who are unavailable or dead, by considering the aspect of natural variations and consistency in handwriting characteristics after an interval of time and age.

\section{Material and methods}

A total number of 540 (60 samples from each age group - 30 samples each from males \& females), has been collected from 9 different age groups i.e. 20 to 25 years, 25 to 30 years, 30 to 35 years, 35 to 40 years, 40 to 45 years, 45 to 50 years, 50 to 55 years, 55 to 60 years and 60 above. The exclusion method for continuous data classification has been adopted to classify above said age groups in this investigation as reported by Gupta $(1996,2011)$. 
The samples were collected from the individuals on A-4 sized plain paper sheet, two handwriting samples in present handwriting with content (a small paragraph consisting 4-8 lines) in English as shown in Figure 1, which was same as the previous written script which is also taken as a sample for comparative study. In total 3 handwriting samples - two in present handwriting (with an interval of 5-10 minutes between the two handwritings) and one old or past handwriting sample collected from each individual (interval ranged from 2-33 years between present and old handwritings). In another A-4 sized paper, handwriting sample of capital letters $(\mathrm{A}-\mathrm{Z})$, small letters $(\mathrm{a}-\mathrm{Z})$ which was supposed to show significant variations as well as digits (0-9) were taken.

The samples were collected with '045 Reynolds fine carbure' ball point pen only for all samples.

The effect of time interval between two handwritings and how this time interval will induce variations in handwriting characteristics have been examined. For this purpose the past and present handwriting samples were collected from different time intervals ranging from 2 years to 33 years. As the range of time interval from 2 years to 33 years is quite large, therefore time intervals were categorized and 10 categories were formed as follows: $\mathrm{I}^{\text {st }}$ category for 2 years gap, II $^{\text {nd }}$ category for 3 years, III $^{\text {rd }}$ category for 4 years gap, IV th category for 5 years gap, $V^{\text {th }}$ category for 6 and 7 years of gap, VI $^{\text {th }}$ category for 8,9 and 10 years of gap, VII ${ }^{\text {th }}$ category for $11,12,13$, 14 and 15 years of gap, VIII ${ }^{\text {th }}$ category for 16, 17, 18 and 19 years of gap, $\mathrm{IX}^{\text {th }}$ category for 22,24 and 25 years of gap and $\mathrm{X}^{\text {th }}$ category for 27 and 33 years of gap from each age group were collected along with their personal details and signatures indicating their consent for handwriting sample.

The collected samples were analyzed by magnifying glass for following class and individual characteristics:

1. Line quality:
a. Speed,
b. Skill,
c. Initial and terminal strokes,
d. Tremor,

2. Rhythm,

3. Spacing between the words,

4. Alignment to baseline, 
5. Connection and strokes between letters,

6. Slant,

7. Size and proportions of letters.

you are cleverer than the 2. PRESENT Each of these girls are good at her This is not such a trook as lexpected Every soldier and every officer was Line Quality

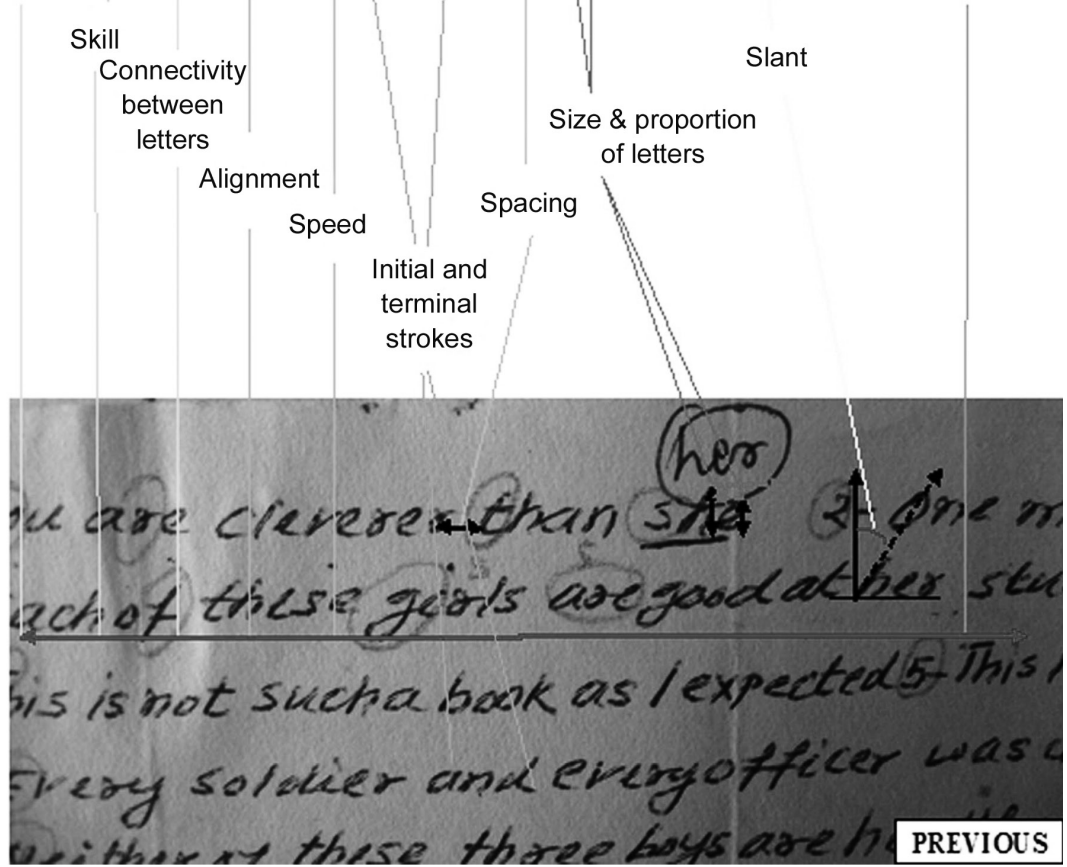

Figure 1. The comparative analysis of handwriting characteristics in past and present handwriting sample 
Speed has been estimated through tapered ends and flying strokes; skill and rhythm was estimated through the consistency and from the flow of their connectivity between letters; spacing between words estimated with ruler - in which if gap is less than $0.5 \mathrm{~cm}$ then it was considered as narrow, between $0.5-1 \mathrm{~cm}$ - even and above $1 \mathrm{~cm}$ - wider; though such categorization does not exist but for the convenience these categories has been formulated for the present study; degree of slant has been observed by using Osborn's scale individually for middle case letters (a, $\mathrm{i}, \mathrm{n}, \mathrm{e}, \mathrm{u})$, for upper case letters $(\mathrm{b}, \mathrm{d}, \mathrm{t}, \mathrm{l}, \mathrm{h})$, for lower case letters (y, g, q) and for combination of more than two of them ( $f, p)$, accordingly the degree of range of slant has been calculated; alignment to baseline has been estimated by placing ruled sheet at the back of sample and viewing it against natural light or transmitted light source (when required); size and proportions of letters measured through transparencies with horizontal lines starting from $1 \mathrm{~mm}$ to $18 \mathrm{~mm}$ with increment of $0.2 \mathrm{~mm}$ each time with the help of Auto CAD software accordingly the handwriting samples (previous and both present handwritings) were examined shown in Figure 1.

\section{Results}

The results of the natural variations with time interval exhibited by handwriting characteristics as observed are depicted in descending order in Table 1.

Table 1. The results in descending order of handwriting characteristics in different categories with Time Intervals $(\mathrm{n}=540)$

\begin{tabular}{|l|c|c|}
\hline $\begin{array}{c}\text { Time Intervals } \\
\text { (Past handwriting } \\
\text { samples) }\end{array}$ & $\begin{array}{c}\text { Categories } \\
\text { of Time } \\
\text { Intervals }\end{array}$ & $\begin{array}{c}\text { Effect of natural variations on handwriting char- } \\
\text { acteristics (descending order) }\end{array}$ \\
\hline 2 Years & I & $\begin{array}{l}\text { Connectivity btw the letters }<\text { Spacing btw the } \\
\text { words }<\text { Alignment to baseline }<\text { Slant }<\text { Initial and } \\
\text { terminal strokes }\end{array}$ \\
\hline 3 Years & II & $\begin{array}{l}\text { Connectivity btw the letters }<\text { Spacing btw the } \\
\text { words }<\text { Initial \& terminal strokes, Alignment to } \\
\text { baseline, Slant }<\text { Rhythm }<\text { Tremor }\end{array}$ \\
\hline
\end{tabular}




\begin{tabular}{|l|c|l|}
\hline 4 Years & III & $\begin{array}{l}\text { Connectivity btw the letters }<\text { Slant, Spacing } \\
\text { btw the words }<\text { Alignment to baseline }<\text { Rhythm } \\
<\text { Initial \& terminal strokes }<\text { Tremor }\end{array}$ \\
\hline 5 Years & IV & $\begin{array}{l}\text { Connectivity btw the letters }<\text { Spacing btw the } \\
\text { words }<\text { Alignment to baseline }<\text { Initial \& termin- } \\
\text { al strokes, Slant }<\text { Tremor }<\text { Rhythm }\end{array}$ \\
\hline 6 and 7 Years & V & $\begin{array}{l}\text { Connectivity btw the letters }<\text { Slant, Spa- } \\
\text { cing btw the words }<\text { Initial \& terminal strokes, } \\
\text { Rhythm }<\text { Alignment to baseline }<\text { Tremor, Speed }\end{array}$ \\
\hline 8,9 and 10 Years & VI & $\begin{array}{l}\text { Connectivity between the letters }<\text { Alignment to } \\
\text { baseline }<\text { Spacing btw words }<\text { Slant, Initial \& } \\
\text { terminal strokes }<\text { Tremor, Speed }<\text { Rhythm }\end{array}$ \\
\hline and 15 Years & VII & $\begin{array}{l}\text { Connectivity btw the letters, Spacing }<\text { Initial } \\
\text { \& terminal strokes, Tremor }<\text { Speed }<\text { Rhythm, } \\
\text { Alignment to baseline, Slant }\end{array}$ \\
\hline $\begin{array}{l}16,17,18 \text { and 19 } \\
\text { Years }\end{array}$ & VIII & $\begin{array}{l}\text { Spacing btw the words }<\text { Connectivity btw the let- } \\
\text { ters }<\text { Slant }<\text { Alignment to baseline }<\text { Rhythm }< \\
\text { Tremor, Initial \& terminal strokes }<\text { Slant and Skill }\end{array}$ \\
\hline $\begin{array}{l}22,24 \text { and } 25 \\
\text { Years }\end{array}$ & IX & $\begin{array}{l}\text { Connectivity btw the letters }<\text { Rhythm, Align- } \\
\text { ment to baseline }<\text { Initial \& terminal strokes, } \\
\text { Tremor }<\text { Slant and Spacing btw the words, Speed. }\end{array}$ \\
\hline 27 and 33 Years & X & $\begin{array}{l}\text { Alignment to baseline, Tremor, Spacing btw the } \\
\text { words, Rhythm, Slant, Speed and Skill }\end{array}$ \\
\hline
\end{tabular}

In $\mathrm{I}^{\text {st }}$ category, maximum variations has been observed in Connectivity between letters while minimum variations were found in initial and terminal strokes. In II $^{\text {nd }}$ and III ${ }^{\text {rd }}$ category, maximum variations have been depicted by Connectivity between letters and minimum in Tremors. In VI ${ }^{\text {th }}$ category, maximum variations have been noted in Connectivity between letters and minimum in Rhythm. In $\mathrm{V}^{\text {th }}$ category, maximum variations have been found in Connectivity between letters and minimum in Speed. In VI ${ }^{\text {th }}$ category, maximum variations have been observed in Connectivity between letters and minimum in Rhythm. In VII ${ }^{\text {th }}$ category, maximum variations have been noticed in Connectivity between letters and minimum in Rhythm, alignment to baseline and slant. In VIII ${ }^{\text {th }}$ category, maximum variations have been observed in Spacing between the words and minimum variations in Skill. In IX ${ }^{\text {th }}$ category, maximum variations have been depicted by Connectivity between letters and minimum variations in Speed, slant and spa- 
cing between words. In $\mathrm{X}^{\text {th }}$ category, maximum variations were observed in Tremor and minimum variations were found in Slant.

In $\mathrm{I}^{\text {st }}$ category ( 2 years), natural variations were very much evident in connectivity between letters, Spacing between the letters, Alignment to baseline, Slant and Initial and terminal strokes. In II ${ }^{\text {nd }}$ category (3 years), along with the above mentioned characteristics, rhythm and tremor has also depicted variations. In category $\mathrm{V}^{\text {th }}$ (6 and 7 years), incorporating the above characteristics, variations has also been observed in Speed. At last skill has shown variation along with the other characteristics in VIII ${ }^{\text {th }}$ category $(16,17,18$ and 19 years). In overall maximum variations have been depicted by connectivity between letters in which variations were noticed from category $\mathrm{I}^{\text {st }}$ i.e. at 2 years of time interval than the rest of the handwriting characteristics. A minimum variation has been observed in Skill, which exhibited its existence in category VIII ${ }^{\text {th }}$ i.e. at 17 years of time interval.

\section{Discussion}

Handwriting characteristics depicting variations in them with time interval is a new insight research so as to determine which handwriting characteristic has depicted variations at which time interval. In the present research the time intervals ranging from 2 to 33 years were clubbed in 10 categories of the time intervals and the distribution of samples showing variations has been performed accordingly in the present investigation. The handwriting characteristics arranged in descending order of their variation on the basis of the findings, maximum variations have been reported in Connectivity between letters, Spacing and alignment, whereas minimum variations have been noted in skill and speed characteristics of handwriting. Bafra and Asicioglu (1998) have undertaken the research on the effect of time in handwriting. They have collected two samples from 50 individual with a gap of 5 years and have observed that size \& proportion of letters, slant and writing quality, which has more variations due to time than the rest of the characteristics, and these findings are in disagreement with the observations made from present research. Though this research is considered as recent and rare as the time interval ranged 
from 2 years to 33 years and the authors have not found much related studies or literature on the natural variations with this much of large time interval prior to this, therefore no comparison can be made. And further authenticity using large number of samples and in different populations can provide highly significant information.

\section{Conclusion}

In today's era on commencing with a case, contemporary writings are foremost requisite and on unavailability of them as if writer is no more alive or having poor physical/ health condition that resists the writer to reproduce handwriting in a similar manner or because of any accident cannot produce handwriting now with accustomed hand, in such cases it is believed that this research work will provide useful information as being a new mode of investigation and will surely aid document experts to undertake these cases and to reach out a correct opinion. With the due effect of the findings gathered from the present investigation the cases lacking in contemporary handwritings can be undertaken with ease by taking into account the handwriting characteristics which are prone to variations (connectivity between letters, alignment and spacing) along with those which remain unaffected and intact by showing consistency (skill and speed) in due course or age and time. With throughout consistency observed in skill and speed, they are proven to be the most useful, promising and reliable handwriting characteristics in handwriting analysis with increasing passage of time. Connectivity between letters and alignment with increasing time interval has shown utmost natural variations in them and therefore they have established themselves as treacherous.

\section{Acknowledgements}

The senior author (Dr Shruti Gupta) is highly thankful to UGC for the award of Senior Research Fellowship and providing the financial assistance to carry out the research work. We are thankful to all sources and persons who have contributed in carrying out this research work and in the collection of samples for the present study. 


\section{References}

Bafra J. and Aşicioglu F. (1998), Effects of Time in Handwriting, Proceeding 6th Indo Pacific Congress on Legal Medicine and Forensic Sciences, Kobe, Japan, pp. 890 893.

Dawson G.A. (1987), "Internal Consistency in Handwriting”, Canadian Society of Forensic Science Journal 20(2), pp. 57-60.

Gupta S., Garg R.K. and Nath S. (2012), "The influence of Natural variations on handwriting characteristics from different age groups with time gap", Turkish Journal of Forensic Science 11(3), pp. 11-20.

Gupta S.C. and Kapoor V.K. (1996), Fundamental of Applied Sciences, 3. ed. - reprint, Sultan Chand \& Sons, India, pp. 36-48.

Gupta S.P. (2011), Statistical Methods, 4. ed., Sultan Chand \& Sons, India, pp. 110-160. Hilton O. (1984), Scientific Examination of Questioned Documents, Elsevier Science Publishing Co.lnc., New York, pp. 56-67.

Huber A.R. and Headrick A.M. (1999), Handwriting Identification Facts and Fundamentals, CRC Press, Boca Raton, London, pp. 73-141.

Kapoor T.S., Kapoor M. and Sharma G.P. (1985), "Study of the Form and extent of natural variations in genuine writing with age", Journal of the Forensic Science Society 25(5), pp. 371-375.

Kelly J.S. and Lindblom B.S. (2006), Scientific Examinations of Questioned Documents, 2. ed., CRC Press, Taylor \& Francis group, pp. 9-14, 47-144.

Shrihari S. (2002), "Individuality of Handwriting", J. Forensic Sci. Soc. 47(4), pp. 106109.

\section{Summary}

In the present investigation an attempt has been made to extract out natural variations with time interval, a total of 540 (60 samples from each age group - 30 samples each from males \& females) collected from 9 different age groups, that is two handwriting samples in present handwriting (with an interval of 5-10 minutes between the two handwritings) with content same as that of previous written script (old handwriting) which is also taken as a sample for comparative study with time interval ranged from 2-33 years between present and old handwriting. It has been found that connectivity between letters, alignment and spacing are highly significant characteristic along with those which remain unaffected and intact by showing consistency in skill and speed in due course or age and time. The findings of the present study will assist in the cases which are lacking in contemporary handwritings and can be undertaken with ease by taking into account the handwriting characteristics which are prone to variations.

Keywords: asynchronous writing, natural variations, time interval, contemporary, consistency.

Nowa Kodyfikacja Prawa Karnego 45, 2017

(C) for this edition by CNS 